\title{
Silent myocardial ischaemia in patients referred for coronary bypass surgery because of angina: a comparison with patients whose symptoms were well controlled on medical treatment
}

\author{
DAVID MULCAHY, JENNIFER KEEGAN, DAVID LINDSAY, JANE SPARROW, \\ AMANDA PARK, CHRISTINE WRIGHT, KIM FOX \\ From the National Heart Hospital, London
}

SUMMARY The frequency and characteristics of silent ischaemia were prospectively studied in $114^{\circ}$ patients with confirmed coronary artery disease and angina. Fifty seven patients who had angina that was not adequately controlled by standard medications were referred for elective coronary $\vec{c}$ artery bypass surgery (group 1). Fifty seven other patients had symptoms that were well controlled 5 on medical treatment (group 2). Patients underwent treadmill exercise testing $(n=109)$ and $48_{-}^{\Phi}$ hours of ambulatory ST segment monitoring (total 5125 hours). Patients in group 1 had moreo severe coronary artery disease and a shorter time to $1 \mathrm{~mm}$ ST segment depression and maximal exercise. Twenty two patients in group $1(38 \%)$ and 16 in group $2(28 \%)$ had $\geqslant 1$ episode of silento ischaemia during 48 hours of ST monitoring. There was no significant difference in the mean $\leq$ frequency of silent ischaemic episodes in 24 hours between the two groups (group $10.72 v$ group 2 0.64 ); however, the mean frequency of painful ischaemic episodes in 24 hours was greater in group $\bar{\alpha}$

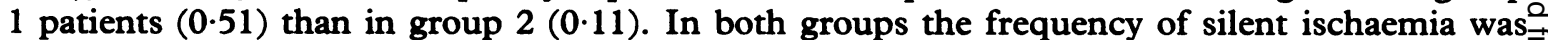
significantly related to a positive exercise test, as was the total duration of silent ischaemia. The $\frac{O}{3}$ circadian variation of silent ischaemia showed a peak of episodes in the evening in both groups.

The frequency of silent ischaemia in patients with coronary artery disease and angina receiving. standard antianginal medications was not related to the severity of symptoms, but was significantly related to a positive exercise test. Thirty three percent of the patients studied had evidence of silento ischaemia during $\mathbf{4 8}$ hours of ambulatory ST segment monitoring; however, only four patients $(3.5 \%)$ had frequent $(\geqslant 5)$ daily episodes of silent ischaemia.

The introduction of ambulatory ST segment monitoring has allowed us to study patients with coronary artery disease and angina during their daily lives, and it has been shown that ST segment change, the electrocardiographic hallmark of ischaemia, occurs in the absence of angina or its equivalents in most cases. ${ }^{1-3}$ ST segment change represents true ischaemia in patients with coronary artery disease. ${ }^{45}$ Acute myocardial infarction occurs without symptoms in about $25 \%$ of cases, ${ }^{6}$ and the prognosis is as serious as that of myocardial infarction accompanied

Requests for reprints to Dr David Mulcahy, National Heart Hospital, Westmoreland Street, London W1M 8BA.

Accepted for publication 31 January 1989 by pain. Because there is concern that silent myocar- 0 dial ischaemia may be causally related to acute myocardial infarction ${ }^{7}$ and sudden death, ${ }^{8}$ it has been proposed that we should investigate patients for the presence of silent ischaemia and treat all ischaemia. or Many investigators have established the frequency 0 and characteristics of silent ischaemia; however, such ${ }_{\omega}^{N}$ studies have included patients not taking routineo antianginal medications. ${ }^{139}$ But most patients witho confirmed coronary artery disease and angina usually receive antianginal treatment. Investigation of $?$ patients in this setting may be more relevant to 0 assessing silent myocardial ischaemia in clinicalo practice.

We studied 114 patients with confirmed coronary artery disease and varying degrees of angina who 
were receiving standard antianginal medications, firstly, in order to investigate whether the frequency of silent ischaemia is related to the level of symptoms and, secondly, to establish the frequency and characteristics of silent ischaemia in patients with coronary artery disease receiving standard antianginal treatment.

\section{Patients and methods}

One hundred and fourteen patients (101 men) aged $30-74$ years (mean 55.5 years) with proven coronary artery disease ( 21 single, 44 two vessel, 49 three vessel disease) and angina were studied between May 1987 and May 1988 to establish the relation between silent myocardial ischaemia and symptoms. We graded angina according to the classification of the Canadian Cardiovascular Society. ${ }^{10}$ Group 1 consisted of 57 patients who, despite adequate antianginal therapy, had poorly controlled anginal symptoms (grade III/ IV) and were referred for elective coronary artery bypass surgery. Group 2 consisted of 57 patients whose angina was well controlled on standard antianginal treatment (grade $\mathrm{I} / \mathrm{II}$ ) and were due for further review as outpatients in six months to one year. Inclusion criteria included the presence of clinically significant coronary artery disease and angina that required regular antianginal medication. We excluded patients taking medication known to affect the ST segment, those with significant conduction disorders, and patients referred for surgery primarily for prognostic rather than symptomatic reasons.

All patients underwent cardiac catheterisation by either the Judkins or the Sones technique. All angiograms were independently reported by one of two radiologists. A significant stenosis was taken to be a $\geqslant 70 \%$ reduction in luminal diameter of a major vessel.

\section{AMBULATORY ST SEGMENT MONITORING}

For ambulatory ST segment monitoring we used pregelled electrodes to record two bipolar leads, an anterior lead (CM5), and an inferior lead. The sites and methods of application of these electrodes have been described elsewhere. ${ }^{11}$ Two channel recordings were then obtained on magnetic tape by a frequency modulated dual channel recorder (Oxford Medilog 2, frequency response $0.05-40 \mathrm{~Hz}$ ). All tapes were visually analysed at $60-120$ times normal speed by an Oxford Medilog MA 20 analyser, and all printouts were recorded at $25 \mathrm{~mm} / \mathrm{s}$. Significant ST segment depression was defined as planar or downsloping ST segment shift of $\geqslant 1 \mathrm{~mm}$ measured $0.08 \mathrm{~s}$ after the $J$ point and persisting for more than one minute. Significant ST segment elevation was defined as an upward shift of the ST segment of $\geqslant 1 \mathrm{~mm}$ at the J point compared with the resting recording. Changes in the $T$ wave vector were not regarded as evidence of myocardial ischaemia unless they were accompanied by significant $S T$ segment changes.

All ambulatory monitoring was performed outside hospital after each patient had been referred either for elective surgery or for routine outpatient follow up. All patients were encouraged to continue with their normal daily activities. During the period of monitoring, patients kept a detailed angina diary, recording the time of each episode of pain, the activity at the onset of symptoms, and the requirement for glyceryl trinitrate. They pressed an event marker on the ambulatory monitor at the onset of symptoms.

\section{TREADMILL EXERCISE TESTING}

One hundred and nine patients underwent maximal symptom limited treadmill exercise testing according to the modified Bruce protocol. Electrocardiograms were recorded at the start of exercise and every three minutes of exercise, and whenever chest pain, hypotension, or significant ST depression developed. A test was regarded as positive if there was ST segment depression of $\geqslant 1 \mathrm{~mm}$ that was planar or downsloping $0.08 \mathrm{~s}$ after the $\mathrm{J}$ point. Exercise was limited by the development of chest pain, dyspnoea, exhaustion, intermittent claudication, complex ventricular arrhythmias, or hypotension.

\section{ANTIANGINAL MEDICATIONS}

All patients were taking routine antianginal medications at the time of investigation. Thirty two patients were on one drug (18, $\beta$ blocker; 12 , calcium antagonist; and two, nitrate); 52 were on two drugs $(28, \beta$ blocker + calcium antagonist; $15, \beta$ blocker + nitrate, and nine, calcium antagonist + nitrate). A further 30 patients were receiving a $\beta$ blocker, calcium antagonist, and nitrate. All patients were also taking short acting nitrates as required.

\section{STATISTICAL ANALYSIS}

We compared the frequency and duration of ischaemic episodes with other variables within groups 1 and 2 by the Mann-Whitney $U$ test, and variables between groups 1 and 2 by the $t$ test or the Mann-Whitney $U$ test as appropriate. A p value of $<0.05$ was regarded as significant. A two harmonic Fourier fit was applied to the hourly frequencies of silent ischaemia.

\section{Results}

The two groups were similar for mean age (group 1 
$56.5 v$ group 254.5 years) and male sex (group $153 v$ group 248 ), and had a similar number of positive exercise tests (group $139 v$ group 230 ) and hours of ST segment monitoring (group $12564 v$ group 2 2561 hours). There was no significant difference between groups in terms of previous myocardial infarction, history of smoking, hypertension, diabetes, or a family history of coronary artery disease. All patients in group 1 had grade III $(n=32)$ or grade IV $(n=25)$ angina, and those in group 2 had grade $I(n=30)$ or grade II $(n=27)$ angina. Table 1 shows the degree of coronary artery disease, the exercise test, and the antianginal medications taken by the two groups. Group 1 patients had more severe coronary artery disease $(p<0.001)$ and a shorter time to pain ( $p<0.001$ ). ST segment depression $(p<0.001)$, and maximal exercise $(p<0.001)$ on treadmill exercise testing. Although the number of routine antianginal medications taken by group 1 patients (2.09) was not different from that of group 2 patients $(1.86)(p=0.09)$, group 1 patients were more likely to be taking combination treatment $(p<$ 0.05).

\section{AMBULATORY MONITORING DATA}

A total of 38 patients (33\%) had 154 episodes of silent ischaemia during 5125 hours of ambulatory monitoring. Table 2 shows the findings on ambulatory $S T$ segment monitoring in the two groups. There was no significant difference between groups in the mean frequency of silent ischaemic episodes per 24 hours or their total duration. The mean frequency of painful ischaemia in 24 hours was significantly greater in group 1 patients (group $10.52 v$ group 2 $0.11, p<0.01$ ), as was the mean frequency of pain without ST segment change (group $11.57 v$ group 2 $0.98, \mathrm{p}<0.01$ ).

Table 1 Severity of coronary artery disease, exercise test, and number of antianginal medications in the two groups

\begin{tabular}{|c|c|c|c|}
\hline & $\begin{array}{l}\text { Group 1 } \\
(n=57)\end{array}$ & $\begin{array}{l}\text { Group } 2 \\
(n=57)\end{array}$ & $p$ \\
\hline $\begin{array}{l}\text { Coronary artery disease: } \\
1 \text { vessel } \\
2 \text { vessel } \\
3 \text { vessel }\end{array}$ & $\begin{array}{r}5 \\
16 \\
36\end{array}$ & $\left.\begin{array}{l}16 \\
28 \\
13\end{array}\right\}$ & $<0.001$ \\
\hline $\begin{array}{l}\text { Exercise test: } \\
\text { Positive } \\
\text { Negative } \\
\text { Time to maximum exercise }\end{array}$ & $\begin{array}{l}39 \\
15\end{array}$ & $\left.\begin{array}{l}30 \\
25\end{array}\right\}$ & NS \\
\hline $\begin{array}{l}\text { (min) } \\
\text { Time to } 1 \mathrm{~mm} \text { ST } \\
\text { depression (min) } \\
\text { Time to pain (min) }\end{array}$ & $\begin{array}{l}7 \cdot 16 \\
5 \cdot 60 \\
(n=39) \\
5 \cdot 53 \\
(n=46)\end{array}$ & $\begin{array}{l}9 \cdot 73 \\
8 \cdot 08 \\
(\mathbf{n}=30) \\
7 \cdot 73=29) \\
(n=29)\end{array}$ & $\begin{array}{l}<0.001 \\
<0.001 \\
<0.001\end{array}$ \\
\hline $\begin{array}{l}\text { Antianginal medications: } \\
\text { Single } \\
\text { Multiple }\end{array}$ & $\begin{array}{l}10 \\
46\end{array}$ & $\left.\begin{array}{l}21 \\
36\end{array}\right\}$ & $<0.05$ \\
\hline
\end{tabular}

Table 2 Mean number and duration of episodes of silent and painful ischaemia and mean number of episodes of pain without $S T$ segment change in the two groups

\begin{tabular}{|c|c|c|c|}
\hline & $\begin{array}{l}\text { Group 1 } \\
(n=57)\end{array}$ & $\begin{array}{l}\text { Group } 2 \\
(n=57)\end{array}$ & $p$ \\
\hline $\begin{array}{l}\text { Silent ischaemic episodes: } \\
\text { Mean no/24 } \mathrm{h} \\
\text { Mean duration } / 24 \mathrm{~h}(\mathrm{~min})\end{array}$ & $\begin{array}{r}0 \cdot 72 \\
14 \cdot 50\end{array}$ & $\begin{array}{r}0 \cdot 64 \\
17 \cdot 60\end{array}$ & $\begin{array}{l}\text { NS } \\
\text { NS }\end{array}$ \\
\hline $\begin{array}{l}\text { Painful ischaemic episodes: } \\
\text { Mean no/24 h } \\
\text { Mean duration } / 24 \mathrm{~h} \text { (min) }\end{array}$ & $\begin{array}{r}0.52 \\
10.50\end{array}$ & $\begin{array}{l}0.11 \\
3.95\end{array}$ & $\begin{array}{l}<0.001 \\
<0.01\end{array}$ \\
\hline $\begin{array}{l}\text { Episodes of pain without ST } \\
\text { segment changes: } \\
\text { Mean no/24 h }\end{array}$ & 1.57 & 0.98 & $<0.01$ \\
\hline
\end{tabular}

There was no difference between groups in the $\frac{\vec{\sigma}}{\sigma}$ mean duration of silent ischaemia per 24 hours $\vec{t}$ (group $114.5 \mathrm{~min} v$ group $217.6 \mathrm{~min}, \mathrm{p}=\mathrm{NS}$ ); however, the duration of painful ischaemia was $ᄋ$ significantly greater in group 1 (group $110.5 \mathrm{~min} v-$ group $23.95 \mathrm{~min}, \mathrm{p}<0.01$ ).

The number of patients with multiple daily episodes ( $\geqslant 5 /$ day) of silent ischaemia was recorded $\vec{\oplus}$ (fig 1). Four patients $(3.5 \%)$ had five or more $\stackrel{\infty}{0}$ episodes per day (two from group 1 and two from: group 2). A further seven patients had more than two but less than five episodes per day. Ninety per cent of all patients had two or fewer episodes of silent ischaemia per day.

\section{AMBULATORY MONITORING AND EXERCISE TESTING}

One hundred and nine patients had an exercise test with which to compare the results of ambulatory monitoring. Figure 2 shows the relation between silent ischaemia on ambulatory monitoring and a

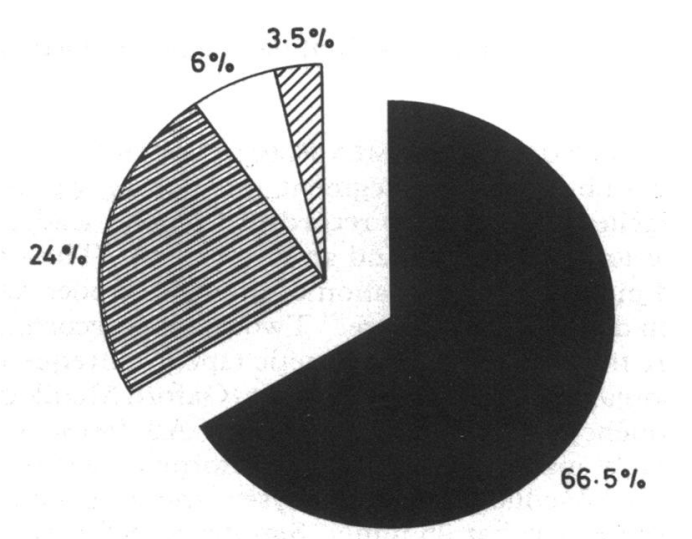

No episodes
$\square>2$ and $<5$ episodes $/ 24 \mathrm{~h} \square \geqslant 5$ episodes $/ 24 \mathrm{~h}$

Fig 1 Frequency of episodes of silent ischaemia per 24 hours $\triangle$ in 114 patients on treatment. 


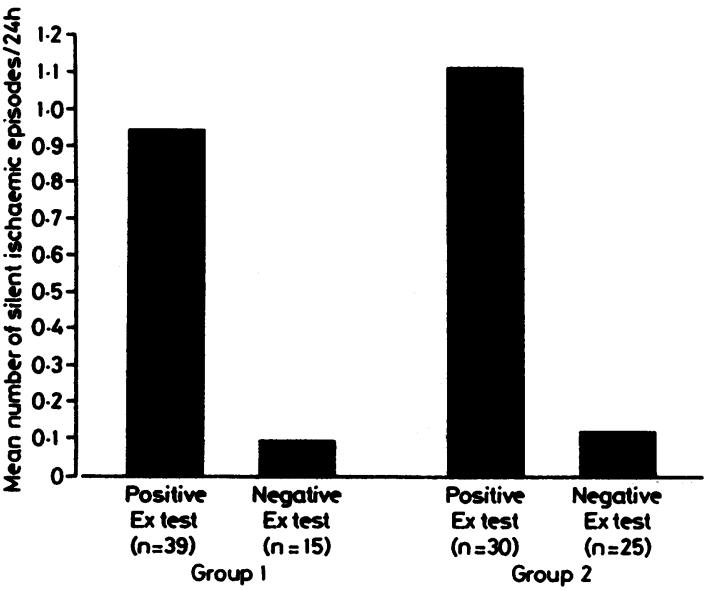

Fig 2 Relation between the mean frequency of silent ischaemic episodes and a positive or negative exercise test in both groups.

positive or negative exercise test in both groups. The presence of silent ischaemia was significantly related to a positive exercise test in both groups $(p<0.01$, $p<0.01$ ). The frequency of painful ischaemia was also related to a positive exercise test $(p<0.01)$, and such pain occurrred predominantly in the more symptomatic group 1 patients, who also developed angina significantly more frequently during exercise than group 2 patients (group $146 v$ group 229 , $p<0.001$ ). The mean duration of silent ischaemia over 24 hours was also related to a positive exercise test in both groups (group 1 positive test $19.4 \mathrm{~min}$, negative test $1.9 \mathrm{~min}, \mathrm{p}<0.02$; group 2 positive test $30.7 \mathrm{~min}$, negative test $3.3 \mathrm{~min}, \mathrm{p}<0.01$ ).

\section{AMBULATORY MONITORING AND OTHER VARIABLES}

There was no significant relation between the frequency of silent ischaemia and either the severity of coronary artery disease or the number of medications taken by the patients. Assessment of the circadian pattern of silent ischaemia in all 114 patients showed a primary peak of episodes in the evening and a secondary one in the morning (fig 3). Although we were unable to gain meaningful information on the effects of all combinations of medications on the circadian variation of silent ischaemic episodes because there were too few patients and ischaemic episodes, we were able to study the relation between the pattern of silent ischaemic episodes and use of $\beta$ blockers, either alone or in combination $(n=$ 91). Again this showed a primary peak in episodes in the evening.

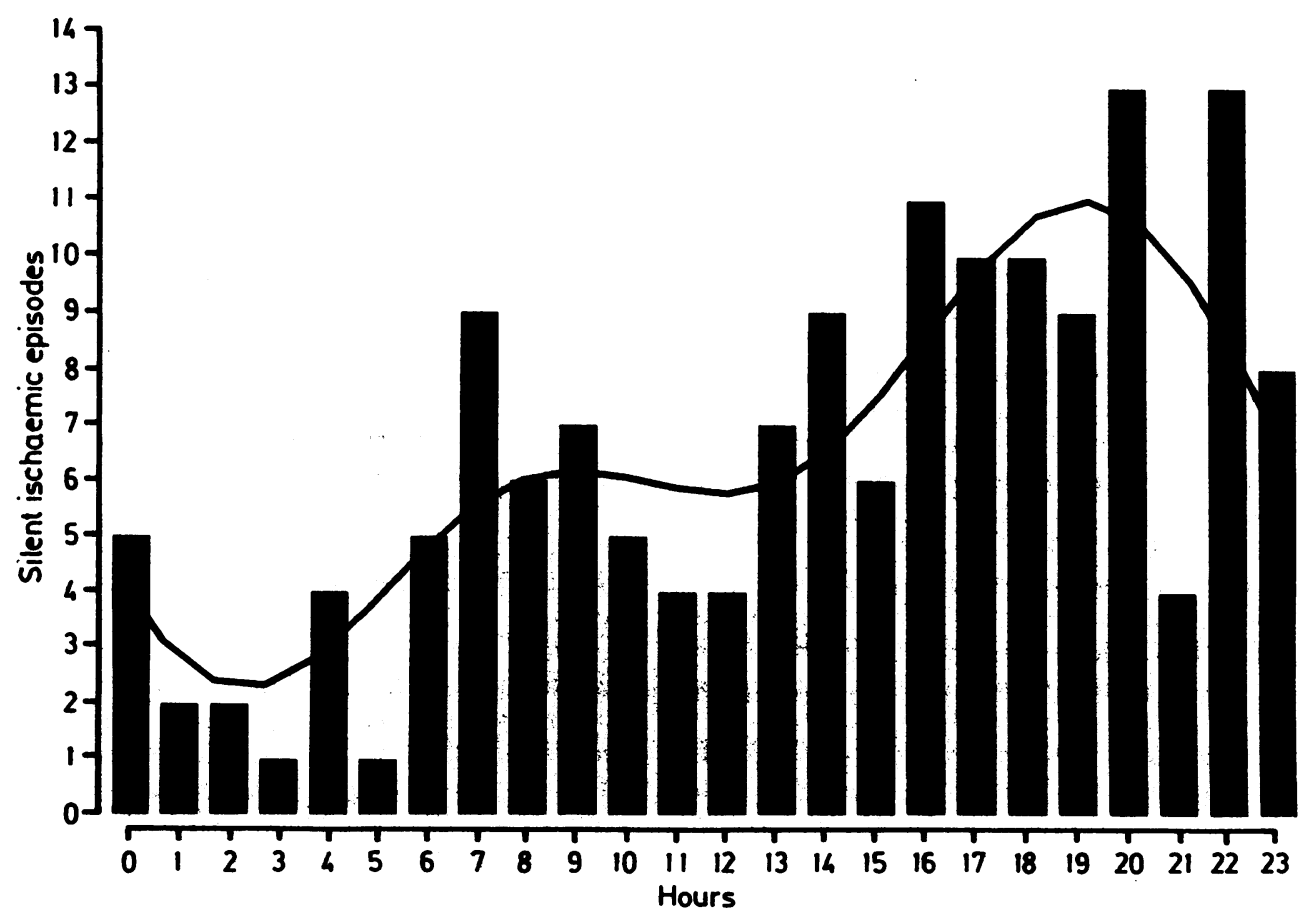

Fig 3 Circadian pattern (with a bimodal fit superimposed) of silent ischaemic episodes in 114 patients on treatment. 


\section{Discussion}

Many workers who have defined the frequency and characteristics of silent myocardial ischaemia in patients with coronary artery disease have selected patients with a positive exercise test ${ }^{1912}$ or those who are not receiving routine antianginal treatment at the time of investigation..$^{139}$ This present study allows us to assess the frequency of silent ischaemia in an "unselected" group of symptomatic patients with significant coronary artery disease who were taking standard medications. This group of patients is more representative of a general population of patients with proven coronary artery disease and angina, most of whom are treated with antianginal medications.

We studied patients in two groups, defined by their angina symptoms according to the criteria of the Canadian Cardiovascular Society. ${ }^{10}$ In those patients with symptoms that were poorly controlled on medical treatment, the ratio of silent to painful episodes (1.39:1) was much lower than in earlier reports, ${ }^{1-3}$ whereas in those whose symptoms were well controlled on medical treatment the high ratio of silent to painful ischaemia persisted $(5 \cdot 65: 1)$. Like Quyyumi et al $^{13}$ we found that a patient's symptoms did not relate to the frequency of silent ischaemia; however, we found that patients with inadequately controlled symptoms did have more painful ischaemia and more pain without ST segment change.

It is not clear why some patients seem to be less aware of their ischaemia, particularly in a study group such as this where all patients had anginal symptoms to a greater or lesser extent. Proposed theories include a generalised defective perception of painful stimuli, ${ }^{14}$ altered sensibility to pain, ${ }^{15}$ and a defective anginal warning system. ${ }^{16}$ The explanation for the silent ischaemia in this group of patients is likely to be multifactorial. It is somewhat surprising that patients whose symptoms are well controlled have a similar amount of silent ischaemia to those who are restricted by symptoms and who have significantly worse exercise tests. ${ }^{3}$ Perhaps patients who are less restricted by angina push themselves harder in their daily activities.

In an earlier study we found that about half of all patients with confirmed coronary artery disease had evidence of silent ischaemia on ambulatory monitoring when they were not taking routine antianginal treatment. ${ }^{3}$ In the present study of patients with coronary artery disease and angina who were receiving standard antianginal treatment, one third had evidence of silent ischaemia on ambulatory monitoring; the mean frequency and total duration of silent ischaemia, however, were much reduced, as might be expected with the use of standard antianginal medi- cations, which have been reported to be effective in $\stackrel{\mathbb{D}}{\stackrel{D}{ }}$ reducing the frequency of silent ischaemia. ${ }^{17}$ It ${ }_{c}$ remains to be established whether combination treatment is more beneficial than single drugs in treating silent ischaemia. Studies of larger numbers of 0 patients should clarify this. Nor is it certain that silent ischaemia is associated with an adverse prog- $\frac{\bar{c}}{\sigma}$. nosis in patients with stable angina, or that medica- $\mathbb{Q}$ tions affect that prognosis. A recent report has suggested that in patients with stable angina and a

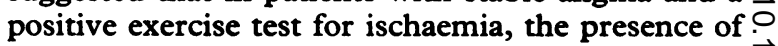
silent ischaemia during ambulatory monitoring iden- $\vec{\omega}$ tifies a subgroup of patients at increased risk of an $\stackrel{\omega}{\circ}$ early unfavourable outcome. ${ }^{18}$

As in published reports ${ }^{311} 19$ in patients who were not taking antianginal drugs we showed a relation $\vec{\sigma}$ between the frequency of silent ischaemia and a $\vec{t}$ positive exercise test, irrespective of medications or $\mathscr{A}$ the level of symptoms a patient suffers. This finding $ᄋ$ is important because it allows us to identify, by a standard investigation, patients at increased risk of $\subseteq$ having silent ischaemia during their daily lives, and $\underset{\mathbb{D}}{ }$ also suggests that similar mechanisms underlie the $\vec{\oplus}$ development of ischaemia in the exercise and 8 ambulatory setting.

We were unable to show any significant relation between the frequency of silent ischaemia and the severity of coronary artery disease in patients receiving treatment. This may have been because the numbers we studied were too small. In a previous $\varrho$ study in patients with coronary artery disease not $\overrightarrow{\overrightarrow{0}}$ taking routine treatment there was a significant relation between the frequency of silent ischaemia and the severity of coronary disease; but only when those with three vessel and single vessel coronary disease were compared. Considerable overlap was noted between those groups with differing levels of coronary disease. ${ }^{3}$

Others reported a significant peak of silent ischaemic episodes in the morning waking hours when patients with coronary artery disease were not 0 taking treatment. ${ }^{2021}$ This morning peak was confirmed for acute myocardial infarction..$^{22}$ We have previously shown that $\beta$ adrenergic blockade eliminates the primary morning peak in episodes of silent or ischaemia, with the primary peak occurring in the $N$ evening, ${ }^{20}$ and $\beta$ blockade has also been shown to $N$ eliminate the morning peak of acute myocardial $\omega$ infarction. $^{22}$ The circadian variation of silent ischaemic episodes in our present study group, who were taking standard antianginal treatment, corres- $\stackrel{\oplus}{\rightarrow}$ ponds closely to that previously shown for patients 0 receiving a $\beta$ blocking agent, ${ }^{20}$ with the primary peak in episodes in the evening at a time when myocardial $\underset{\mathbb{D}}{\mathbb{D}}$ oxygen demand might be expected to be low. This pattern probably results from the fact that almost all 
patients were receiving a $\beta$ blocker as part of their treatment, and suggests that patients on $\beta$ blocking agents are less likely to develop silent ischaemia in the morning. The effects of various combination treatments on the circadian pattern of silent ischaemia still require elucidation.

The frequency of silent myocardial ischaemia in patients with coronary artery disease and angina who are receiving standard medical treatment is not related to the degree of symptoms that a patient suffers, though painful ischaemia is more common in those whose symptoms are inadequately controlled by medication. The frequency and total duration of silent and painful ischaemia are significantly related to a positive exercise test, suggesting similar pathophysiological mechanisms. In patients treated with $\beta$ blockers, either alone or as part of combination treatment, the peak of silent ischaemic episodes occurs in the evening. We found that two thirds of patients with coronary artery disease and angina of varying severity receiving medical treatment had no silent ischaemia during 48 hours of ambulatory monitoring, and only 11 patients $(9.6 \%)$ had more than two episodes of silent ischaemia a day.

We thank the British Heart Foundation for their support.

\section{References}

1 Cecchi AC, Dovellini EV, Marchi F, Pucci P, Santoro GM, Fazzini F. Silent myocardial ischaemia during ambulatory electrocardiographic monitoring in patients with effort angina. J Am Coll Cardiol 1983; 1:934-9.

2 Tzivoni D, Gavish A, Benhorin J, Karen A, Stern S. Myocardial ischaemia during daily activities and stress. Am J Cardiol 1986;58:47B-50B.

3 Mulcahy D, Keegan J, Crean P, et al. Silent myocardial ischaemia in chronic stable angina: a study of its frequency and characteristics in 150 patients. $\mathrm{Br}$ Heart J 1988;60:417-23.

4 Deanfield JE, Selwyn AP, Chierchia S, et al. Myocardial ischaemia during daily life in patients with stable angina: its relation to symptoms and heart rate changes. Lancet 1983;i:753-8.

5 Levy RD, Shapiro LM, Wright C, Mockus LJ, Fox KM. The haemodynamic significance of asymptomatic ST segment depression assessed by ambulatory pulmonary artery pressure monitoring. Br Heart J 1986;56:526-30.

6 Kannel WB, Abbott RD. Incidence and prognosis of unrecognised myocardial infarction. An update on the Framingham Study. N Engl J Med 1984;311:1144-7.

7 Assey ME, Walters GL, Hendrix GH, Carabello BA, Usher BW, Spann JF. Incidence of acute myocardial infarction in patients with exercise induced silent myocardial ischaemia. Am J Cardiol 1987;59: 497-500.

8 Sharma B, Asinger R, Francis GS, Hodges M, Wyeth RP. Demonstration of exercise induced painless myocardial ischaemia in survivors of out of hospital ventricular fibrillation. Am J Cardiol 1987;59:740-5.

9 Deanfield JE, Shea M, Ribiero P, et al. Transient ST segment depression as a marker of myocardial ischaemia during daily life. Am J Cardiol 1984; 54:1195-200.

10 Campeau L. Grading of angina pectoris [Letter]. Circulation 1976;54:522-3.

11 Quyyumi AA, Mockus L, Wright C, Fox KM. Morphology of ambulatory ST segment changes in patients with varying severity of coronary artery disease. Investigation of the frequency of nocturnal ischaemia and coronary spasm. Br Heart J 1985;53: 186-93.

12 Cohn PF, Lawson WE. Characteristics of silent myocardial ischaemia during out-of-hospital activities in asymptomatic angiographically documented coronary artery disease. $\mathrm{Am} J$ Cardiol 1987;59:746-9.

13 Quyyumi AA, Wright CM, Mockus LJ, Fox KM. How important is a history of chest pain in determining the degree of ischaemia in patients with angina pectoris? Br Heart J 1985;54:22-6.

14 Glazier JJ, Chierchia S, Brown MJ, Maseri A. Importance of generalised defective perception of painful stimuli as a cause of silent myocardial ischaemia in chronic stable angina pectoris. Am J Cardiol 1986; 58:667-72.

15 Droste C, Roskamm H. Experimental pain measurements in patients with asymptomatic myocardial ischaemia. J Am Coll Cardiol 1983;1: 940-5.

16 Cohn PF. Silent myocardial ischaemia in patients with a defective anginal warning system. Am J Cardiol 1980; 45:697-701.

17 Frishman WH, Teicher M. Antianginal drug therapy for silent myocardial ischaemia. Am Heart $J$ 1987; 114:140-7.

18 Rocco MB, Nabel EG, Campbell S, et al. Prognostic importance of myocardial ischaemia detected by ambulatory monitoring in patients with stable coronary artery disease. Circulation 1988;78:877-84.

19 Campbell S, Barry J, Rebecca GS, et al. Active transient myocardial ischaemia during daily life in asymptomatic patients with positive exercise tests and coronary artery disease. Am J Cardiol 1986;57:1010-6.

20 Mulcahy D, Keegan J, Cunningham D, et al. Circadian variation of total ischaemic burden and its alteration with anti-anginal agents. Lancet 1988;ii:755-9.

21 Rocco MB, Barry J, Campbell S, et al. Circadian variation of transient myocardial ischaemia in patients with coronary artery disease. Circulation 1987;75: 395-400.

22 Muller JE, Stone PH, Turi ZG, et al. Circadian variation in the frequency of onset of acute myocardial infarction. $N$ Engl J Med 1985;313:1315-22.

23 Willich SN, Linderer T, Wegscheider K, Schroder R. Increased risk of myocardial infarction in the morning [Abstract]. J Am Coll Cardiol 1988;11:28A. 